Short Communication

\title{
Corrosion Resistance of Niobium Microalloyed HRB500 Mild Steel Rebar in the Alkaline Concrete Pore Solution
}

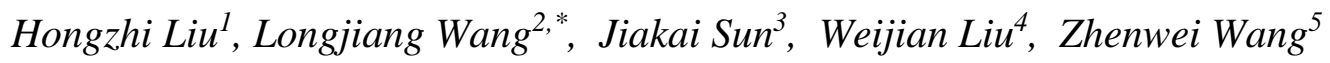 \\ ${ }^{1}$ Shandong Urban Construction Vocational College, Jinan, 250103, China \\ ${ }^{2}$ Collelge of River and Ocean Engineering, Chongqing Jiaotong University, Chongqing, 400074, \\ China \\ ${ }^{3}$ China Coal Research Institute, Beijing 100013, China \\ ${ }^{4}$ Department of Architecture and Engineering, Zhongyuan University of Technology, Zhengzhou \\ 450007, China \\ ${ }^{5}$ School of Civil Engineering, North China University of Technology, Beijing,100144, China, \\ *E-mail: bylongjiang@126.com
}

doi: $10.20964 / 2020.07 .09$

Received: 4 february 2020 / Accepted: 27 March 2020 / Published: 10 June 2020

\begin{abstract}
Recently, micro-alloyed steel rebars had been evaluated extremely to improve corrosion resistance of steel rebars in corrosive environments which intended to enhance the service life of reinforced concrete structures. In this study, corrosion resistance of niobium $(\mathrm{Nb})$ microalloyed HRB500 mild steel rebar in the alkaline concrete pore solution were investigated by electrochemical technique. Electrochemical impedance spectroscopy (EIS), cyclic voltammetry (CV) and potentiodynamic polarization techniques were used to study the effect of $\mathrm{Nb}$ content on corrosion behavior of steel rebars. The $\mathrm{CV}$ results showed that the current density in zero potential decreased by increasing the $\mathrm{Nb}$ content, indicating that a small amount of $\mathrm{Nb}$ microalloy in steel rebars facilitated the stability of the formed passive layers. The polarization plots showed that the steel rebar with $0.055 \mathrm{wt} \% \mathrm{Nb}$ content had a smaller corrosion current-density than the other samples which was in the passive state during the test. The EIS results indicated that the double-layer capacitance value decreased with the addition of $\mathrm{Nb}$ content, resulting in enhanced protective capacity. The surface morphology of the samples revealed that the surface of steel rebar with $0.055 \mathrm{wt} \% \mathrm{Nb}$ was smooth and no visible corrosion was observed.
\end{abstract}

Keywords: Corrosion resistance; Niobium microalloyed steel rebar; Electrochemical impedance spectroscopy; Simulated concrete pore solution

FULL TEXT 
(C) 2020 The Authors. Published by ESG (www.electrochemsci.org). This article is an open access article distributed under the terms and conditions of the Creative Commons Attribution license (http://creativecommons.org/licenses/by/4.0/). 